\title{
HIV infected men who have sex with men in Israel: knowledge, attitudes and sexual behavior
}

\author{
Zohar Mor ${ }^{1,2^{*}}$, Dan Turner ${ }^{2,3}$, Yuval Livnat ${ }^{4}$ and Itzchak Levy ${ }^{2,5}$
}

\begin{abstract}
Background: HIV-infected (HIVI) men who have sex with men (MSM) may transmit HIV to their sero-discordant sex partner/s. This study assesses the knowledge, attitudes and sex-practices of Israeli HIVI-MSM.

Methods: This cross-sectional study compared HIVI-MSM to self-reported HIV-uninfected (HIVU) MSM by using anonymous questionnaires that were distributed in AIDS-treatment centers and gay-related internet-sites in 2015. Unprotected anal intercourse (UAl) in the last 6 months was the outcome variable.

Results: Of 300 HIVI-MSM and 1299 HIVU-MSM, UAI with sero-discordant/unknown-status partner/s was performed by $12.1 \%$ and $17.9 \%$, respectively, $p=0.02$. UAI with sero-discordant/unknown-status among HIVI-MSM and HIVUMSM was associated with the type of partnership: $37.7 \%$ vs. $52.4 \%$ for steady partner $/ s, 19.0 \%$ vs. $39.9 \%$ for sexbuddies and $23.5 \%$ vs. $24.0 \%$ for casual partner/s $(p<0.001, p=0.01, p=0.6)$, respectively. On these occasions, HIVIMSM were more likely to be receptive during UAl: $92.3 \%, 87.5 \%$ and $83.3 \%$ for steady partner/s, sex buddies and casual partner/s, respectively. In cases HIVI-MSM performed UAI, 31.3\% expected their partner/s to share responsibility for condom-use vs. 9.7\% of HIVU-MSM.

HIVI-MSM were involved in risky sexual-behaviors, such as substances-use, earlier sexual debut and sex for money. HIVI-MSM were more likely to disclose their HIV-status with their partner before sex and demonstrated better knowledge about HIV-transmission than HIVU-MSM.

Conclusion: HIVI-MSM performed UAI with sero-discordant/unknown-status partner/s less frequently than HIVUMSM. Their condom-use practices were associated with the type of partner, and were lower for casual vs. steady partners or sex-buddies. HIVI-MSM tended to use sero-adaptive strategies to reduce the potential risk of HIVtransmission to their sero-discordant/unknown-status partner/s.
\end{abstract}

Keywords: Aids, Disclosure, Gay men, Sero-discordant, Unprotected anal intercourse

\section{Background}

The burden of HIV/AIDS in Israel has increased during the last 15 years, especially among men who have sex with men (MSM), who comprise $\sim 40 \%$ of all males infected with HIV [1], and it is estimated that the prevalence of HIV among MSM in 2011 was $0.7-1.0 \%$ [2]. This trend is related to the declining death rate among HIV-infected individuals due to the beneficial outcomes of the anti-retroviral treatment (ART). The predicted life

\footnotetext{
* Correspondence: zohar.mor@telaviv.health.gov.il

${ }^{1}$ Tel Aviv Department of Health, 12 Ha'arba'a St, 6473912 Tel Aviv, Israel

${ }^{2}$ Faculty of Medicine, Tel Aviv University, Tel Aviv, Israel

Full list of author information is available at the end of the article
}

expectancy has improved dramatically and is now only $\sim 8$ years shorter than that of non-HIV infected individuals [3]. The success of ART has also changed the perception of HIV/AIDS-infection from a lethal disease to a chronic condition.

The beneficial effects of ART provide HIV-infected MSM a full and relatively healthy life, while keeping their social circles preserved. They therefore have opportunities to maintain a sex network, while being able to potentially transmit the infection to other healthy sex partners. Some HIV-infected MSM who achieve undetectable viral load level may decide to perform unprotected anal sex (UAI), considering themselves as not 
being able to transmit the virus [4]. Other HIV-infected MSM may perform UAI with their sex partner/s following a disclosure that they are HIV-infected - a phenomenon called 'sero-sorting' [5]. In parallel, the perceived risk of HIV infection in the gay community has declined, which may influence MSM who are uninfected with HIV to participate in risky sexual behavior- a phenomenon called 'AIDS treatment optimism' [6]. HIV-infected MSM may also employ additional risk reduction strategies, such as choosing the receptive rather than the insertive role in anal intercourse, or performing oral rather than anal sexa phenomenon called 'strategic positioning' [7].

Nevertheless, these strategies may not provide full protection. As HIV-incidence among MSM in Israel is increasing and HIV-infected MSM are the potential reservoir for further HIV-transmissions in the gay community, it is therefore necessary to study their knowledge, attitudes and practices in order to understand the dynamics of HIV transmission in Israel and to design targeted interventions for HIV-infected MSM.

\section{Methods}

This cross-sectional study compared the knowledge, attitudes and sex-practices of HIV-infected MSM with that of HIV-uninfected MSM. The study instrument included anonymous questionnaires which were distributed in 2015 in AIDS treatment centers, and gay-related venues, events for HIV-infected individuals and on the internet (Additional file 1). Electronic banners advertising the survey were distributed in gay social network sites. MSM who clicked the banners were referred to webquestionnaires, where participants were asked different questions, depending on their HIV status, type of sex partners and sexual behavior. No financial incentive was offered.

The study size was calculated for a minimal difference of $2-3 \%$ in number of UAI between HIV-infected and non-HIV infected MSM who attend AIDS treatment centers. Study size for each arm was calculated with 5\% type I error and 95\% type II error, suggesting a minimum of 202 participants in each arm.

HIV-infected MSM were included if they had been treated with ART longer than one year and had visited one of the AIDS treatment centers in central Israel more than once, having been tested for CD4 count and plasma viral load, and if they had also reported that they had performed anal sex with another man during the last year. HIV-uninfected MSM were included if they had had anal sex with at least one other male partner during the last year, and had reported they were not known to be infected with HIV, as per a test performed within the last year. MSM younger than 18 years of age, and those who had not been living in Israel for more than one year were excluded.
Independent variables included demographic attributes, knowledge about HIV-transmission, attitudes towards condoms and harm reduction strategies, party drugs and condom-use as well as the reasons for not using condoms, sexual behavior in the last six months with different types of partners and additional risk behaviors. Dependent variables included self-reported HIV sero-status and UAI.

Statistical analysis: Characteristics of HIV-infected MSM were compared with those of HIV-uninfected MSM, and also between MSM who performed UAI in the last six months with those who did not. Univariate analysis was performed using the chi-square test for categorical variables and using the Student $t$-test for continuous variables in cases in which they were normally distributed or the Mann-Whitney test for variables which were not distributed normally. $P$ values lower than $5 \%$ were regarded as statistically significant. Variables which were statistically significant in the univariate analysis were included in the multivariate analysis in the logistic regression to identify attributes predicting UAI after excluding collinearity, such as party drugs and alcohol.

\section{Results and discussion}

This study included $300 \mathrm{HIV}$-infected and 1299 uninfected MSM who completed the questionnaires. Of the HIV-infected MSM, 185 (61.9\%) were recruited electronically and 114 (38.1\%) completed manual questionnaires, while among HIV-uninfected it was 1068 (82.2\%) and 231 (17.8\%), respectively. HIV-infected MSM were less educated than HIV-uninfected, more likely to selfidentify themselves as gay men and more commonly reported previous sexually transmitted diseases (STD) diagnoses (Table 1). They were also more aware of the beneficial effect of ART in preventing HIV transmission. HIV-infected MSM were more likely to perform UAI than HIV-uninfected MSM, yet when they did, it was commonly performed with other HIV-concordant sexual partner/s. HIV-infected MSM were more likely to meet their sexual partners in saunas, clubs or through introduction by friends than HIV-uninfected participants. They used party drugs more commonly and were involved in additional risky sexual behaviors, such as earlier sexual debut and sex for money. In addition, they used more anti-depressant drugs in the last 6 months and reported dissatisfaction with their own health in comparison to HIV-uninfected MSM.

Of all MSM who were in committed relationships, HIV-infected MSM were more likely to have serodiscordant/unknown HIV-status steady partner/s than HIV-uninfected MSM. HIV-infected were less likely to perform UAI with their sero-discordant/unknown HIVstatus steady partner/s than HIV-uninfected MSM. In 
Table 1 Characteristics of men who have sex with men, by HIV status

\begin{tabular}{|c|c|c|c|c|}
\hline Characteristic & & HIV-infected N = $300(\%)$ & HIV-uninfected $N=1299(\%)$ & $P$ \\
\hline \multirow[t]{6}{*}{ Demographic } & Age in years (mean $\pm \mathrm{Sd}$ ) & $35.0 \pm 9.6$ & $33.9 \pm 9.6$ & 0.05 \\
\hline & Israeli born & $282(86.2)$ & $1157(89.0)$ & 0.06 \\
\hline & Less than average income $e^{a}$ & $181(65.4)$ & $790(68.5)$ & 0.1 \\
\hline & Jew & $215(93.5)$ & $1232(95.3)$ & 0.2 \\
\hline & University education $^{\mathrm{a}}$ & $164(55.2)$ & $823(63.4)$ & $<0.001$ \\
\hline & Self-identified gay & $273(96.1)$ & $1446(85.6)$ & $<0.001$ \\
\hline \multirow[t]{4}{*}{ Previous STD diagnoses } & Syphilis & $72(24.1)$ & $29(2.2)$ & $<0.001$ \\
\hline & Hepatitis C & $10(3.3)$ & $6(0.5)$ & 0.002 \\
\hline & Hepatitis B & $10(3.3)$ & $21(1.6)$ & 0.06 \\
\hline & Any STD ${ }^{a, b}$ & $171(57.2)$ & $401(30.9)$ & $<0.001$ \\
\hline \multirow[t]{3}{*}{ Knowledge about HIV transmission } & $\begin{array}{l}\text { Treated HIV-infected individual has } \\
\text { low risk of transmission }\end{array}$ & $198(76.4)$ & $444(41.8)$ & $<0.001$ \\
\hline & $\begin{array}{l}\text { In case the condom breaks, I will } \\
\text { recommend PEP to my partner }\end{array}$ & $175(67.8)$ & $737(69.3)$ & 0.7 \\
\hline & $\begin{array}{l}\text { HIV infected man can perform UAI } \\
\text { with serocon-cordant partner }\end{array}$ & $125(48.1)$ & $332(31.2)$ & $<0.001$ \\
\hline \multirow{7}{*}{$\begin{array}{l}\text { Reasons for not using condoms } \\
\text { in the last } 6 \text { months }\end{array}$} & I was too horny & $27(52.9)$ & $236(54.3)$ & 0.9 \\
\hline & I had a sero-concordant partner & $35(68.6)$ & $169(38.9)$ & $<0.001$ \\
\hline & I was under influence of substances & $10(21.7)$ & $81(18.6)$ & 0.6 \\
\hline & $\begin{array}{l}\text { Each partner is responsible for his } \\
\text { own health }\end{array}$ & $15(31.3)$ & $42(9.7)$ & $<0.001$ \\
\hline & Condom breaks the intimacy & $21(45.7)$ & $157(36.1)$ & 0.2 \\
\hline & I am sick of using condoms & $19(41.3)$ & $151(34.7)$ & 0.4 \\
\hline & I am losing my erection & $12(26.1)$ & $117(26.9)$ & 1.0 \\
\hline \multirow[t]{2}{*}{ Raising HIV issue before/ during sex } & $\begin{array}{l}\text { HIV issue is always been raised } \\
\text { before sex }\end{array}$ & $245(77.9)$ & $1027(75.6)$ & 0.5 \\
\hline & I raise the issue of HIV & $80(40.6)$ & $324(39.6)$ & 1.0 \\
\hline \multirow{7}{*}{$\begin{array}{l}\text { Where do you mostly meet your sex } \\
\text { partners? }\end{array}$} & Phone application & $210(85.7)$ & $942(86.7)$ & 0.6 \\
\hline & Facebook & $25(0.8)$ & $140(12.9)$ & 0.4 \\
\hline & Park & $21(9.1)$ & $52(4.8)$ & 0.02 \\
\hline & Sauna & $33(14.3)$ & $74(6.8)$ & $<0.001$ \\
\hline & Club & $46(19.5)$ & $115(10.6)$ & $<0.001$ \\
\hline & Friends & $34(14.5)$ & $91(8.4)$ & 0.006 \\
\hline & Gym & $13(5.7)$ & $27(2.5)$ & 0.02 \\
\hline \multirow[t]{2}{*}{ Substances in the last 6 months } & Use party drugs & $197(75.5)$ & $622(57.5)$ & $<0.001$ \\
\hline & Alcohol & $118(59.0)$ & $546(89.2)$ & $<0.001$ \\
\hline \multirow[t]{3}{*}{ Additional risky sexual behavior } & Age first sexual debut (years) & $17.0 \pm 4.4$ & $18.4 \pm 4.9$ & $<0.001$ \\
\hline & Ever been paid for sex & $49(18.8)$ & $140(13.5)$ & 0.02 \\
\hline & I take more risks when I am abroad & $32(16.6)$ & $85(10.6)$ & 0.03 \\
\hline Psychiatrics & $\begin{array}{l}\text { Medical use of anti-depressant drugs } \\
\text { in the last } 6 \text { months }\end{array}$ & $80(31.3)$ & $142(13.7)$ & $<0.001$ \\
\hline \multirow[t]{2}{*}{ General subjective health status } & Dissatisfied with my own health ${ }^{c}$ & $28(11.1)$ & $57(5.5)$ & 0.003 \\
\hline & I am healthier than my friends & $64(25.1)$ & $384(37.0)$ & $<0.001$ \\
\hline
\end{tabular}

STD Sexually transmitted infections

PEP Post exposure prophylaxis

UAI Unprotected anal intercourse

adjusted for age

byphilis, Neisseria gonorrhea, Chlamydia trachomatis, genital warts, hepatitis B or C

'Dissatisfied vs. satisfied 
cases in which UAI was performed with their serodiscordant/unknown HIV-status steady partner/s, HIVinfected MSM tended to take the receptive role (Table 2).

Of all MSM who had sex buddy/ies, HIV-infected MSM were less likely to have sero-discordant/unknown HIV status partner/s than HIV-uninfected MSM. HIVinfected MSM reported less UAI with sero-discordant/ unknown HIV status sex buddy/ies than HIV-uninfected MSM. In cases in which UAI was performed with their sero-discordant/unknown HIV-status sex buddy/ies, HIV-infected MSM were more likely to take the receptive role.

Of all MSM who had casual partner/s, HIV-infected MSM were less likely to have sero-discordant/unknown HIV-status casual sex partner/s than HIV-uninfected MSM. No statistical difference was found in the rate of UAI with sero-discordant/unknown HIV-status partner/ $s$ between HIV-infected and uninfected MSM. In cases in which UAI was performed with sero-discordant/unknown HIV-status casual sex encounter/s, HIV-infected MSM were more likely to take the receptive role.

Generally, HIV-infected MSM were less likely to perform UAI with sero-discordant/unknown HIV-status encounter/s than HIV-uninfected (39 [12.1\%] vs. 232 [17.9\%], respectively, $p=0.02$ ). The rate of UAI among HIV-infected MSM with their sero-discordant/unknown HIV-status encounter/s was associated with the type of partnership. For example, UAI were more commonly performed with their sero-discordant/unknown HIVstatus steady partner/s (66.3\%), followed by sex-buddies (24.7\%) and lowest with casual partner/s (23.1\%), $p=0.02$.

Of all HIV-infected, 109 (66.5\%) reported their last viral load. Of those, $89(81.7 \%)$ were undetectable and 20 (18.3\%) had more than 50 copies. There were no differences in UAI between those who achieved viral suppression and those who did not (data not shown).

MSM in this study who performed UAI were more commonly younger and more likely to identify themselves as gay men than those who use condoms consistently and they also had more previous STD than those who used condoms constantly (Table 3 ). Their knowledge about post exposure prophylaxis (PEP) was inferior, yet they were more likely to raise the issue of HIV before sex, had more steady partners and more commonly used party drugs, alcohol and erectile dysfunction medications. In addition, they had earlier first sexual debut than those who used condoms. In the multivariate analysis, insufficient knowledge about PEP, raising the issue of HIV before/during sex, having a steady partner, reporting of a more common use of party drugs or erectile dysfunction medications and being at an early age for the first sexual debut was associated with UAI. HIV-infection was not found to predict UAI in the multivariate analysis.

Table 2 Unprotected anal intercourse (UAI) by HIV status and type of partner

\begin{tabular}{|c|c|c|c|c|}
\hline Variable & & HIV infected $N=300$ & HIV uninfected $N=1299$ & $P$ \\
\hline \multirow[t]{4}{*}{ Steady partner } & $\begin{array}{l}\text { Number of men with steady partner } \\
\mathrm{N}(\% \text { of all men) }\end{array}$ & $104(34.7)$ & $448(34.5)$ & 1.0 \\
\hline & $\begin{array}{l}\text { Sero-discordant/unknown-status steady partner } \\
\mathrm{N} \text { (\% of all men with steady partner) }\end{array}$ & $69(66.3)$ & $63(14.1)$ & $<0.001$ \\
\hline & $\begin{array}{l}\text { UAl with sero-discordant/unknown-status steady partner } \\
\mathrm{N} \text { (\% of all sero-discordant/unknown-status steady partners) }\end{array}$ & $26(37.7)$ & $33(52.4)$ & $<0.001$ \\
\hline & $\begin{array}{l}\text { Receptive UAI } \\
\text { N (\% of all UAI with sero-discordant/unknown-status steady partner) }\end{array}$ & $24(92.3)$ & $23(69.7)$ & 0.04 \\
\hline \multirow[t]{4}{*}{ Sex buddy } & $\begin{array}{l}\text { Number of men with sex buddy } \\
\mathrm{N}(\% \text { of all men) }\end{array}$ & $117(39.0)$ & $525(40.4)$ & 0.9 \\
\hline & $\begin{array}{l}\text { Sero-discordant/unknown-status sex buddy } \\
\text { N (\% of all men with sex buddy) }\end{array}$ & $29(24.7)$ & $253(48.2)$ & $<0.001$ \\
\hline & $\begin{array}{l}\text { UAI with sero-discordant/unknown-status sex buddy } \\
\mathrm{N} \text { (\% of all sero-discordant/unknown-status partners) }\end{array}$ & $8(27.6)$ & $98(38.7)$ & 0.01 \\
\hline & $\begin{array}{l}\text { Receptive UAI } \\
\text { N (\% of all UAI with sero-discordant/unknown-status sex buddy) }\end{array}$ & $7(87.5)$ & $47(48.0)$ & 0.01 \\
\hline \multirow[t]{4}{*}{ Casual partner } & $\begin{array}{l}\text { Number of men with casual partner } \\
\mathrm{N} \text { (\% of all men) }\end{array}$ & $217(72.3)$ & $912(70.2)$ & 0.7 \\
\hline & $\begin{array}{l}\text { Sero-discordant/unknown-status casual partner } \\
\text { N (\% of all men) }\end{array}$ & $51(23.5)$ & $757(80.3)$ & $<0.001$ \\
\hline & $\begin{array}{l}\text { UAl with sero-discordant/unknown-status casual partner } \\
\mathrm{N} \text { (\% of all sero-discordant/unknown-status casual partners) }\end{array}$ & $12(23.5)$ & $182(24.0)$ & 0.8 \\
\hline & $\begin{array}{l}\text { Receptive UAI } \\
\text { N (\% of all UAl with sero-discordant/unknown-status casual partner) }\end{array}$ & $10(83.3)$ & $65(35.7)$ & $<0.001$ \\
\hline
\end{tabular}


Table 3 Univariate and multivariate analyses of sexual behaviors of men who have sex with men, by condom use

\begin{tabular}{|c|c|c|c|c|c|c|}
\hline \multirow[t]{2}{*}{ Characteristic } & & \multicolumn{3}{|l|}{ Univariate analysis } & \multicolumn{2}{|c|}{ Multivariate analysis } \\
\hline & & UAI N = $532(\%)$ & $\begin{array}{l}\text { Always condom } \\
N=1066(\%)\end{array}$ & $P$ & OR $(95 \% \mathrm{Cl})$ & $P$ \\
\hline \multirow[t]{6}{*}{ Demographic } & Age in years (mean $\pm \mathrm{Sd}$ ) & $34.0 \pm 9.8$ & $33.7 \pm 10.4$ & 0.04 & $1.0(0.9-1.1)$ & 0.9 \\
\hline & Israeli born & $480(90.2)$ & $969(91.2)$ & 0.6 & & \\
\hline & Less than average income ${ }^{a}$ & $303(61.7)$ & $668(60.4)$ & 0.5 & & \\
\hline & Jew & $487(94.9)$ & $960(95.0)$ & 0.9 & & \\
\hline & University education ${ }^{\mathrm{a}}$ & $313(63.7)$ & $674(61.0)$ & 0.1 & & \\
\hline & Self-identified gay & $472(95.0)$ & $850(86.4)$ & $<0.001$ & $2.2(0.9-5.5)$ & 0.07 \\
\hline \multirow[t]{4}{*}{ Previous STD diagnoses } & HIV-infected & $126(23.7)$ & $223(20.1)$ & 0.01 & $1.2(0.8-1.3)$ & 0.09 \\
\hline & Neisseria gonorrhea & $126(23.7)$ & $138(12.9)$ & $<0.001$ & & \\
\hline & Syphilis & $15(9.6)$ & $50(4.7)$ & $<0.001$ & & \\
\hline & Hepatitis B & $17(3.2)$ & $14(1.3)$ & 0.02 & & \\
\hline \multirow[t]{2}{*}{$\begin{array}{l}\text { Knowledge about HIV } \\
\text { transmission }\end{array}$} & $\begin{array}{l}\text { Treated HIV-infected individual } \\
\text { has low risk of transmission }\end{array}$ & $240(51.3)$ & $402(47.1)$ & 0.1 & & \\
\hline & $\begin{array}{l}\text { In case the condom breaks, I will } \\
\text { recommend PEP to the partner }\end{array}$ & $287(61.2)$ & $625(73.4)$ & $<0.001$ & $2.7(2.0-3.6)$ & $<0.001$ \\
\hline $\begin{array}{l}\text { Raising HIV issue before/ } \\
\text { during sex }\end{array}$ & $\begin{array}{l}\text { HIV issue is usually being raised } \\
\text { before sex }\end{array}$ & $266(50.1)$ & $415(39.1)$ & $<0.001$ & $1.6(1.4-2.6)$ & 0.01 \\
\hline \multirow[t]{3}{*}{ Type of partner } & Steady & $378(71.1)$ & $236(22.1)$ & $<0.001$ & $15.3(10.1-23.7)$ & $<0.001$ \\
\hline & Sex buddy & $227(42.7)$ & $415(38.9)$ & 0.1 & & \\
\hline & Casual & $385(72.4)$ & $796(74.7)$ & 0.2 & & \\
\hline \multirow{7}{*}{$\begin{array}{l}\text { Where do you meet your } \\
\text { sex partners? }\end{array}$} & Phone applications & $399(85.3)$ & $761(88.2)$ & 0.6 & & \\
\hline & Facebook & $61(13.0)$ & $104(12.3)$ & 0.7 & & \\
\hline & Park & $24(5.1)$ & $49(5.8)$ & 0.6 & & \\
\hline & Sauna & $39(8.3)$ & $68(8.0)$ & 0.9 & & \\
\hline & Club & $54(11.4)$ & $107(12.6)$ & 0.6 & & \\
\hline & Friends & $45(9.6)$ & $80(9.4)$ & 0.9 & & \\
\hline & Gym & $10(2.1)$ & $30(3.6)$ & 0.2 & & \\
\hline \multirow{3}{*}{$\begin{array}{l}\text { Substances/ drugs in the } \\
\text { last } 6 \text { months }\end{array}$} & Party drugs & $316(65.7)$ & $503(58.4)$ & 0.005 & $2.0(1.2-3.2)$ & 0.006 \\
\hline & Alcohol & $281(87.8)$ & $383(77.8)$ & $<0.001$ & & \\
\hline & erectile dysfunction medications & $116(35.8)$ & $107(21.8)$ & $<0.001$ & $2.0(1.2-3.5)$ & 0.007 \\
\hline \multirow{3}{*}{$\begin{array}{l}\text { Additional risky sexual } \\
\text { behavior }\end{array}$} & Age first sexual debut (years) & $17.5 \pm 4.6$ & $18.5 \pm 4.9$ & 0.001 & $1.2(1.1-1.2)$ & 0.01 \\
\hline & Was paid for sex & $85(18.7)$ & $109(12.8)$ & 0.05 & & \\
\hline & I take more risks abroad & $134(26.9)$ & $258(23.3)$ & 0.08 & & \\
\hline Psychiatrics & $\begin{array}{l}\text { Medical use of anti-depressant } \\
\text { drugs in the last } 6 \text { months }\end{array}$ & 72 (15.2) & $150(18.3)$ & 0.2 & & \\
\hline $\begin{array}{l}\text { General subjective health } \\
\text { status }\end{array}$ & Dissatisfied with my own health ${ }^{b}$ & $26(5.5)$ & $59(7.2)$ & 0.2 & & \\
\hline
\end{tabular}

OR Odds ratio

$\mathrm{Cl}$ Confidence interval

STD Sexually transmitted infections

PEP Post exposure prophylaxis

UAl Unprotected anal intercourse

${ }^{\text {a Adjusted for age }}$

${ }^{b}$ Dissatisfied vs. satisfied

In this study, $12.1 \%$ of the HIV-infected and $17.9 \%$ of the HIV-uninfected MSM reported UAI with a sero-discordant/unknown HIV-status partner during the previous six months, lower than the range of 13-
51\% UAI during the last year, as reported in a literature review [8]. HIV-infected MSM frequently employed the 'sero-sorting' and 'sero-positioning' strategies, while using condoms more commonly than 
HIV-uninfected MSM during anal intercourse with their sero-discordant/unknown HIV-status sex partners and selecting the receptive role when preforming UAI. HIV-infected MSM also demonstrated a better knowledge regarding HIV prevention and transmission than MSM who were not infected.

Although HIV-infected MSM in this study were involved in behaviors which were associated with a greater sexual risk, such as the use of party drugs, erectile dysfunction medications and early first sexual debut, they were generally more compliant in using condoms with their HIV sero-discordant/unknown HIV-status partners, as also found in another study [9]. However, they reported that they expected that the responsibility of using a condom would be shared by their partner/s. In cases in which the issue of HIV was not raised before sex, then HIV-infected MSM might have assumed that their partner was either careless or sero-concordant, and chose to perform UAI. Shifting the responsibility to the sex partner was found to be associated with additional risky sexual behaviors [10] and also with 'sex on premises venues' or anonymous sex, when there are fewer bonds of social obligations, implying reciprocal care of the sexual encounter/s [11]. The results of this study demonstrate the complexity of disclosure of their HIV status to their partners. On one hand, HIV-infected MSM are probably aware that they are morally and possibly legally obliged [12] to inform their partner of their sero-status, or at least use a condom in anal sex, especially if they are not treated or have not achieved undetectable viral load. On the other hand, they are concerned that the HIV-uninfected partner/s may reject them upon disclosure or that their confidentiality is breached [13]. HIV prevention should therefore include social support for HIV-infected MSM to encourage them to disclose their sero-status to their partner, or use a condom with HIV-discordant/unknown HIV-status partner/s to make personal responsibility more salient, or to adhere to their ART. Concomitantly, HIV-uninfected MSM should also be encouraged to raise the issue of HIV sero-status with their sex partner/s, and be informed that sex with HIV-infected partner/s is safe as long as proper biological or mechanical protection is used, rather than avoiding sex partners whose HIV serostatus is positive $[14,15]$.

A minority of HIV-infected MSM performed UAI with a sero-discordant partner although their viral load was detectable. Yet, in most cases HIV-infected MSM performed UAI with sero-concordant sexual partner/s. In these cases they may be exposed to coinfection with other STD, which may complicate and accelerate HIV disease [16]. It has recently been demonstrated that the rise of syphilis in Israel was fueled by UAI between HIV sero-concordant sex partners [17].
In cases in which HIV-infected MSM in this study performed UAI with HIV sero-discordant/unknown partner/s, they commonly used strategic positioning, while choosing the receptive role in anal sex. These calculated risk-taking strategies may reduce, yet not eliminate, HIV transmission. However, these efforts are not always fully appreciated by those who provide medical and social services for HIV-infected MSM. Providers should rather understand the difficulty of HIV-disclosure, the pursuit of HIV-infected MSM to reach intimacy with the sex partner, and their fear of being stigmatized or rejected, and also be aware of the psychological context that frames condom-use [18]. Providers should maintain an open environment in their clinics when treating HIVinfected MSM, in which patients can appraise their desires and their actions, and evaluate their sexual behaviors and reasons why they engaged in risk-behaviors [19].

Most of the participants in this study were not aware of the HIV sero-status of their casual partners. In the majority of those cases, mutual HIV status was not raised before or during sex, not allowing the encounters to negotiate safer sex practices or perform strategic positioning. Interestingly, HIV-infected MSM had performed more UAI with their sero-discordant/unknown HIVstatus steady partners, and less with their serodiscordant/unknown HIV-status sex buddies or casual partners. This is an additional finding demonstrating the difficulty in maintaining a constant condom use for longer periods with a regular sex partner.

HIV-infected MSM were more likely to use psychiatric drugs and reported that their general health status was inferior to that reported by HIV-uninfected MSM. It is not known whether they used psychiatric medications because they were infected, or that they felt more comfortable using these medications than HIV-uninfected participants did, or that maybe they had used the drugs before they were infected [20]. AIDS treatment centers should employ multidisciplinary approach to HIV-infected MSM, which includes mental care and effective response to additional medical needs of HIV-infected MSM.

The results of this study should be weighed against recent publications describing the success of ART in HIV-infected MSM and its role in preventing HIV transmissions. Although UAI has traditionally been used as a key component in defining risky sexual behavior, there is a growing, largely coherent, body of evidence that HIVinfected MSM who adhere to ART and are virally suppressed may render HIV transmission negligible [21, 22]. This approach can be reinforced by using additional risk-reduction strategies, such as sero-adaptive sex behaviors, strategic positioning, or withdrawal [23]. Notwithstanding, there is also an emerging consensus as to the effectiveness of pre-exposure prophylaxis (PrEP), a course of ART that can be used by HIV-uninfected men 
to prevent seroconversion [24]. PrEP has become more popular among MSM, including those is Israel, and it is the authors' impression that HIV-uninfected MSM are making efforts to get the treatment (purchasing through the internet, during a visit to developing countries, or falsely claim that they were exposed to HIV and ask for PEP, while actually using it as PrEP). The success of these biomedical innovations may justify a fresh perception of UAI by researchers and providers, whether UAI accurately defines risk behavior.

This is the first study in Israel describing knowledge, attitudes and behaviors of HIV-infected MSM, yet it is subject to several methodological limitations. First, the cross-sectional design of the study limits the establishment of causality. A few examples: are HIV-infected MSM involved in risky sexual behavior and therefore become infected or that they were they involved in risky sexual behavior after becoming infected; Did HIVinfected MSM change their role in anal sex to the receptive position because of their HIV-infection in order to decrease the risk of HIV-transmission or that they practiced receptive anal sex prior to their HIV-infection? Second, we used a convenience sample of HIV-infected, which is subject to selection bias and it limits generalizability. Yet, this method is accepted in studies in hard-to-reach populations focusing in sensitive issues, such as sexual behavior, especially among HIV-infected MSM, as they are stigmatized. In order to encourage recruitment and increase heterogeneity, MSM (both HIV-infected and uninfected) were approached both in medical and non-medical settings, and the questionnaires were also available electronically in a popular gayrelated internet site. Third, all data in this study were self-reported and as such potentially subject to social desirability or recall bias. In order to minimize this bias, the information was collected anonymously and pertained only to events which occurred during the last year.

\section{Conclusions}

In summary, HIV-infected MSM performed UAI less frequently with their sero-discordant/unknown HIV-status encounters than HIV-uninfected MSM. HIV-infected MSM tended to used sero-adaptive strategies to reduce the potential risk of HIV-transmission to their serodiscordant/unknown HIV-status partner/s. In those cases in which HIV-infected MSM performed UAI, they reported that a shared responsibility by both partners was expected. In order to increase mutual sero-disclosure, HIV-infected MSM should be encouraged to discuss their HIV status. AIDS treatment center should include mental support for HIV-infected MSM and instruct the patients how to practice safe sex and encourage the discloser of their HIV status to their partners.

\section{Additional file}

Additional file 1: Study questionnaire. (DOCX $35 \mathrm{~kb}$ )

\begin{abstract}
Abbreviations
ART: Anti-retroviral treatment; HIVI: HIV infected; HIVU: HIV uninfected; MSM: Men who have sex with men; PEP: Post exposure prophylaxis; PrEP: Pre-exposure prophylaxis; STD: Sexually transmitted diseases; UAl: Unprotected anal intercourse
\end{abstract}

\section{Acknowledgments}

The Authors thank Ms. Vered Hadas from the AIDS treatment center, Sourasky Medical Center in Tel Aviv for distributing the questionnaires. The Authors also thank Mr. Alon Madar, Mr. Adir Yanko and Mr. Saar Maoz for their assistance in outlining the questionnaires and distributing them in social and electronic venues.

\section{Funding}

This study was partially sponsored by MSD Israel (Merck, Sharp and Dohme (Israel-1996) Company Ltd., a subsidiary of Merck \& Co.). The grant was unsolicited with no involvement of MSD Israel in any aspect of the study.

Availability of data and materials

The data are available upon request from the corresponding author.

\section{Authors' contributions}

ZM initiated the study, performed the statistical analysis and wrote the first draft. DT, YL and IL recruited patients to participate in the study, added comments to the manuscript and approved the final draft. All authors read and approved the final manuscript.

Ethics approval and consent to participate

This study was approved by the Institutional Review Board of the Ministry of Health (089-2013). The Tel Aviv Sourasky and Tel Hashomer Medical centers approved the study.

Consent for publication

Not applicable.

\section{Competing interests}

The authors declare that they have no competing interests.

\section{Publisher's Note}

Springer Nature remains neutral with regard to jurisdictional claims in published maps and institutional affiliations.

\section{Author details}

${ }^{1}$ Tel Aviv Department of Health, 12 Ha'arba'a St, 6473912 Tel Aviv, Israel. ${ }^{2}$ Faculty of Medicine, Tel Aviv University, Tel Aviv, Israel. ${ }^{3}$ AIDS Treatment Center, Sourasky Medical Center, Tel Aviv, Israel. ${ }^{4}$ Israeli AIDS Task Force, Tel Aviv, Israel. ${ }^{5}$ AIDS Treatment Center, Sheba Medical Center, Ramat Gan, Israel.

Received: 5 February 2017 Accepted: 3 October 2017

Published online: 12 October 2017

\section{References}

1. Mor Z, Weinstein R, Grotto I, Levin Y, Chemtob D. Thirty years of HIV in Israel- current epidemiology and future challenges. BMJ Open. 2013;3: e003078.

2. Mor Z, Davidovitch U. Same-sex sexual attraction, behavior and practices of Jewish men in Israel and the association with HIV prevalence. AIDS Care. 2016;28(Suppl 1):64-7.

3. Patterson S, Cescon A, Samji H, et al. Life expectancy of HIV-positive individuals on combination antiretroviral therapy in Canada. BMC Infect Dis. 2015;15:274.

4. Surkan PJ, Li Y, Jacobson LP, et al. Unsafe sexual behavior among gay/ bisexual men in the era of combination antiretroviral therapy (CART). AIDS Behav. 2016; doi:10.1007/s10461-016-1614-4. 
5. Stall R, Duran L, Wisniewski SR, et al. Running in place: implications of HIV incidence estimates among urban men who have sex with men in the United States and other industrialized countries. AIDS Behav. 2009;13(4): 615-29.

6. Daskalopoulou M, Rodger A, Phillips AN, Sherr L, Speakman A, Collins S, et al. Recreational drug use, polydrug use, and sexual behaviour in HIVdiagnosed men who have sex with men in the UK: results from the crosssectional ASTRA study. Lancet HIV. 2014;1(1):e22-31.

7. Mor Z, Dan MHIV. Epidemic among men who have sex with men- behavior surpass science. EMBO Rep. 2012;13:948-53.

8. Van Kesteren NMC, Hospers HJ, Kok G. Sexual risk behavior among HIVpositive men who have sex with men: a literature review. Patient Educ Couns. 2007;65:5-20.

9. Crepaz N, Marks G, Liau A, et al. Prevalence of unprotected anal intercourse among HIV-diagnosed MSM in the United States: a meta-analysis. AIDS. 2009;23(13):1617-29.

10. Wolitski RJ, Flores SA, O'Leary A, et al. Beliefs about personal and partner responsibility among HIV-seropositive men who have sex with men: measurement and association with transmission risk behavior. AIDS Behav. 2007;11(5):676-86.

11. Adam BD. Constructing the neoliberal sexual actor. Cult Health Sex. 2000;7: 333-46.

12. Mor Z, Chemtob D, Hildesheimer G, Leventhal A. AIDS and the privilege for privacy. Harefuah. 2007;146(3):200-5. [in Hebrew with an English abstract]

13. Cook SHHIV. Status disclosure, depressive symptoms, and sexual risk behavior among HIV-positive young men who have sex with men. J Behav Med. 2015;13(3):507-17.

14. Murphy DA, de With JBF, Donohoe S, et al. The need to know: HIV status disclosure expectations and practices among non-HIV-positive gay and bisexual men in Australia. AIDS Care. 2015;27(S1):90-8.

15. O'Leary A, Horvath KJ, Simon Rosser BR. Associations between partnervenue specific personal responsibility beliefs and transmission risk behavior by HIV-positive men who have sex with men (MSM). AIDS Behav. 2013;17(5): 1855-61.

16. Eaton LA, West TV, Kenny DA, et al. HIV transmission risk among HIV seroconcordant and serodiscordant couples: dyadic processes of partner selection. AIDS Behav. 2009:13(2):185-95.

17. Brosh-Nissimov T, Mor Z, Avramovich E, et al. Syphilis outbreak among men who have sex with men in Tel Aviv, Israel, 2008-2010. IMAJ. 2012;14(3):152-6.

18. Starks TJ, Payton G, Golub SA, Weinberger CL, Parsons JT. Contextualizing condom use: intimacy interference, stigma, and unprotected sex. J Health Psychol. 2014;19(6):711-20.

19. Bourne A, Dodds C, Keogh P, Weatherburn P. Non-condom related strategies to reduce the risk of HIV transmission: Perspectives and experiences of gay men with diagnosed HIV. J Health Psycho. 2015; pii: 1359105315581066.

20. Choi SK, Boyle E, Cairney J, et al. Adequacy of Mental Health Services for HIV-Positive Patients with Depression: Ontario HIV Treatment Network Cohort Study. PLoS One. 2016 9;11(6):e0156652.

21. Vernazza $P$, Hirschel $B$, Bernasconi $E_{t}$ et al. Les personnes se'ropositives ne souffrant d'aucune autre MST et suivant un traitement antire'troviral efficace ne transmettent pas le VIH par voie sexuelle [HIV-positive individuals not suffering from any other STD and adhering to an effective antiretroviral treatment do not transmit HIV sexually]. Bulletin des me'decins suisses. 2008;89(5):165-9.

22. Rodger AJ, Cambiano V, Bruun T, et al. Sexual activity without condoms and risk of HIV transmission in Sero-different couples when the HIV-positive partner is using suppressive antiretroviral therapy. JAMA. 2016;316(2):171-81.

23. Jin F, Prestage GP, Mao L, et al. "Any condomless anal intercourse" is no longer an accurate measure of HIV sexual risk behavior in gay and other men who have sex with men. Front Immunol. 2015:6:86.

24. Grant RM, Lama JR, Anderson PL, et al. Pre-exposure chemoprophylaxis for HIV prevention in men who have sex with men. N Engl J Med. 2010;363(27): 2587-99.

\section{Submit your next manuscript to BioMed Central and we will help you at every step:}

- We accept pre-submission inquiries

- Our selector tool helps you to find the most relevant journal

- We provide round the clock customer support

- Convenient online submission

- Thorough peer review

- Inclusion in PubMed and all major indexing services

- Maximum visibility for your research

Submit your manuscript at www.biomedcentral.com/submit

) Biomed Central 